\title{
NBA Draft Lottery Probabilities
}

\author{
Chad R. Florke and Mark D. Ecker \\ Department of Mathematics \\ University of Northern lowa \\ Cedar Falls, lowa 50614-0506 USA
}

Received: November 6, 2003

Accepted: December 1, 2003

\begin{abstract}
We examine the evolution of the National Basketball Association's (NBA's) Draft Lottery by showing how the changes implemented by the Board of Governors have impacted the probabilities of obtaining top picks in the ensuing draft lottery. We explore how these changes have impacted the team with the worst record and also investigate the conditional probabilities of the fourth worst team receiving the third pick. These calculations are conditioned upon two specified teams receiving the first two selections. We show that the probability of the fourth worst team receiving the third pick can be made unconditionally. We calculate the probabilities for the fourth worst team to move up in the draft to receive either the first, second, or third selections, along with its chance of keeping the fourth pick or even dropping in the draft. We find there is a higher chance for the fourth worst team to drop to the fifth, sixth or seventh position than to stay at the fourth position or move up.
\end{abstract}

\section{INTRODUCTION}

\section{a. National Basketball Association (NBA) Draft Lottery History and Evolution}

In all major professional team sports, recruiting amateur players from college, high school, or overseas is vital to the health of the organization. The best available players are highly sought after; the process of determining which new players the various teams choose is called a draft. The draft order indicates which team chooses first, second, etc. Each team is allowed to choose one player in the first round of drafting according to its draft order (although a team may trade its draft pick away, i.e., it may not have a first round selection while another team might have two). The process is repeated to choose a second player for each team, according to the draft order, in the second round. In professional basketball, the draft has only two rounds (compared to seven rounds in professional football).

The draft order for each round is typically determined by the inverse order of the record of finish of the teams, i.e., the number of games won for each team (which may also include playoff wins). For example in football, the team with the worst record (fewest number of wins during the season) will draft first in each round while the best team (the Super Bowl winner) will draft last in each round. In professional basketball, the inverse order of the record of finish is called the initial draft order. A degree of randomness has been introduced to arrive at the final draft order, which is subsequently used to choose the players. In basketball, the worst team is only guaranteed to receive a high chance of getting the first pick; a draft lottery system is used to determine the final draft order.

Unlike football, baseball and hockey, drafting professional athletes into the NBA involves probability theory. From 1966-1984, the NBA draft lottery mandated the teams that finished last in their respective conference (East and West) participated in a coin flip to determine which team drafted first. Thus, the team with the worst record might not receive the first pick in the final draft order; but at worst, it would 
receive the second pick (each with a $50 \%$ chance). The loser of the coin toss would receive the second pick and all remaining teams would subsequently pick in inverse order of their won-loss records [1]. Note that it is not unrealistic for the team with the second worst record in the NBA to receive the third pick in the draft provided they are in the same conference as the team with the worst record in the NBA.

The reasons for implementing the draft lottery system have evolved over concerns of teams deliberately losing games to increase their chance of receiving a higher pick, especially the first pick. The 1984 Houston Rockets, for example, were thought to be deliberately losing or throwing games to increase their final draft position in the subsequent draft. In general, NBA superstars are overwhelmingly high draft picks; there is often a substantial drop in talent after the first handful of draft picks. In the past 25 years, top draft picks who have subsequently won NBA championships include Ervin "Magic" Johnson, James Worthy, Hakeem Olajuwon, David Robinson, Shaquille O'Neal and Tim Duncan. Other first picks, Patrick Ewing, Kenyon Martin and Alan Iverson, have taken their respective teams to the finals after their arrival [2].

In 1985, the NBA Board of Governors expanded the draft lottery from two teams tossing a coin to determine the first pick to the seven teams with the worst records striving for the top pick. In 1989, due to expansion, eleven teams were now vying for the top three picks, i.e., three teams from the eleven would be randomly drawn in the draft lottery to receive the top three final draft positions. This system gave the team with the worst record 11 chances out of 66 to receive the top pick. The second worst team was given ten chances, and the team with the best record (of the eleven non-playoff teams) received one chance. Table 1 contains the 1990 teams and their associated chances for receiving the top pick. The draft lottery affects the draft order of the first round only. In the second round, teams pick in the inverse order of their regular season records, i.e., the final draft order is the same as the initial draft order for round two [1-3].

Under the 1990 draft lottery system in Table 1, which we call the old system, the team with the worst overall record in the
NBA (first in the initial draft order) is assured no worse than the fourth overall position in the final draft order. The second worst team is assured no worse than the fifth overall pick, etc. Thus, instead of having the two worst teams vying for the top pick, this system has the 11 worst teams striving for the top three picks with all remaining teams (the 8 non selected non-playoff teams and all playoff teams) having a final draft order determined by inverse record.

After modification in November 1993, the chances for the teams with the worst record of obtaining the top selection were increased. The lottery chances of the teams with the best records were, in turn, decreased. This system increased the probability of the team with the worst overall record obtaining the first pick from 0.167 to 0.25 . The team with the best overall nonplayoff record had its chance of attaining the first pick reduced from $1.5 \%$ to $0.5 \%$ [1]. As given in the NBA 2003 Year by Year Probabilities, these probabilities appear in Table 2 [3].

The technical procedure for implementing the actual lottery drawing involves 14 ping-pong balls, numbered 1 through 14, placed in a drum and four balls are drawn. When these four balls are drawn out of the 14 total balls, without regard to their order of selection, 1,001 combinations are possible $\left({ }_{14} \mathrm{C}_{4}=1001\right)$. Prior to the lottery drawing, teams are assigned combinations based on their order of finish (their initial draft position) during the regular season [1]. For example, Dallas was assigned 250 of the possible combinations. The Board of Governors reduced the total number of combinations to an even 1000 by disregarding one of the combinations which was not assigned to a team. Table 2 illustrates the chances assigned to each team and the associated probabilities of receiving the top pick.

The most recent alteration to the NBA Draft Lottery system (referred to as the new system) occurred in October of 1995 when two expansion teams, Vancouver and Toronto, were introduced to the NBA. Of the NBA's now 29 teams, 16 will qualify for the playoffs, leaving the 13 non-qualifiers (compared to 11 previously) eligible for the lottery system. Beginning in 1996, the team with the worst record in the lottery continued 


\begin{tabular}{|c|c|c|c|}
\hline Team & $\begin{array}{c}\text { 1989-1990 Regular Season Record } \\
\text { (Games Won - Games Lost) }\end{array}$ & Chances & Probability \\
\hline New Jersey & $17-65$ & 11 & 0.1667 \\
\hline Miami & $18-64$ & 10 & 0.1515 \\
\hline Orlando & $18-64$ & 9 & 0.1364 \\
\hline Charlotte & $19-63$ & 8 & 0.1212 \\
\hline Minnesota & $22-60$ & 7 & 0.1061 \\
\hline Sacramento & $23-59$ & 6 & 0.0909 \\
\hline L.A. Clippers & & 5 & 0.0758 \\
\hline Washington & $31-51$ & 4 & 0.0606 \\
\hline Golden State & $37-45$ & 3 & 0.0455 \\
\hline Seattle & $41-41$ & 2 & 0.0303 \\
\hline Atlanta & $41-41$ & 1 & 0.0152 \\
\hline Totals & & 66 & 1.00 \\
\hline
\end{tabular}

Table 1. 1990 NBA Draft Lottery Probabilities - Old System

\begin{tabular}{|c|c|c|c|}
\hline Team & $\begin{array}{c}\text { 1993-1994 Regular Season Record } \\
\text { (Games Won - Games Lost) }\end{array}$ & Chances & Probability \\
\hline Dallas & $13-69$ & 250 & 0.2500 \\
\hline Detroit & $20-62$ & 164 & 0.1640 \\
\hline Minnesota & $20-62$ & 164 & 0.1640 \\
\hline Milwaukee & $20-62$ & 163 & 0.1630 \\
\hline Washington & $24-58$ & 94 & 0.0940 \\
\hline Philadelphia & $25-57$ & 66 & 0.0660 \\
\hline L.A. Clippers & $27-55$ & 44 & 0.0440 \\
\hline Sacramento & $28-54$ & 27 & 0.0270 \\
\hline Boston & $32-50$ & 15 & 0.0150 \\
\hline L.A. Lakers & $22-49$ & 8 & 0.0080 \\
\hline Charlotte & $41-41$ & 5 & 0.0050 \\
\hline Totals & & 1000 & 1.00 \\
\hline
\end{tabular}

Table 2. 1994 NBA Draft Lottery Probabilities [3]. 
to have a $25 \%$ chance at obtaining the first pick (250 combinations or chances out of 1,000). Teams two through six have slightly fewer combinations, team seven has the same number, teams eight through 12 received more combinations, and the team with the best non-playoff record still received 5. If two teams have the same regular season record, then their combined chances would be shared equally; if their combined chance were an odd number, the extra combination would be randomly assigned [1]. Following the NBA 2003 Year-by-Year Probabilities, Table 3 illustrates the chances at receiving the top pick under this system for the teams involved in the 2001 NBA draft lottery [3].

\section{THE WORST TEAM}

We initially study the worst team's probability of receiving each of the top four picks. Recall, under both the old and new systems, if the team with the worst record (first in the initial draft order) does not get awarded the first, second, or third selections in the final draft order, they are guaranteed the fourth selection. Table 4 details the worst non-playoff team's probability of obtaining each of the first four picks in the NBA Draft where $n_{i}$ is the number of chances (from Tables 1 or 3 , respectively) assigned to the team who received the first pick and $n_{j}$ is the number of chances assigned to the team who ultimately received the second pick. Each team's chance of obtaining the first selection is based solely on their number of combinations assigned from either Table 1 or 3 . For the probabilities of receiving the second and third final draft positions, each respective probability will depend upon the outcomes for the first and second selections. This is a conditional probability that depends on the various team(s) receiving the previous pick(s). The probability of obtaining the fourth pick will be one minus the sum of the previous three probability calculations.

In the 2002-2003 NBA season, Cleveland and Denver tied for the worst record. Cleveland received the top pick in the draft lottery and subsequently chose high school player LeBron James. Denver wound up third, drafting Carmello Anthony from Syracuse.

\section{THE FOURTH WORST TEAM - CONDITIONAL PROBABILITIES OF RECEIVING THE THIRD PICK}

The goal of the next several sections is to compare probabilities of a team that does not have the worst record receiving a higher final draft position than their initial draft position under both the old and new systems. We examine the team with the fourth initial draft position; it will receive a final draft position ranging from the top pick to no worse than the seventh pick (in the event the top three final draft positions are teams with better records than the team with the fourth worst record).

In this section, we examine the fourth worst non-playoff team's chances of receiving the third pick, i.e., the chances of the team with the fourth initial draft position moving up to the third final draft position. Here, the conditional probability involves the team with the fourth worst record receiving the third pick given a set of two teams who are awarded the first two picks. The two systems are compared utilizing two probability tables where the rank of these teams is listed along the axes of each table. In the 2000-2001 season, the Vancouver Grizzlies had the fourth worst regular season record, i.e., their initial draft position is four as seen in Table 3. Thus, they receive 120 out of 1,000 combinations of attaining the first pick in the 2001 NBA Draft. The chance that Vancouver will move up to the third final draft position is a conditional probability, where, in general, $\mathrm{P}$ (The fourth worst team receives the third pick given one team with rank i AND a team with rank j receive the first and second picks, respectively). Table 5 demonstrates all the conditional probabilities of the fourth worst team receiving the third pick given a pair of teams (teams $i$ and $j$ ) under the old system; Table 6 has similar calculations under the new system. Note that Tables 5 and 6 are really symmetric (if thought of as a matrix); we only present the upper triangle to ease readability. For example in Table 6 , the probability Vancouver receives the third final draft position given the teams with initial draft positions 1 and 2 (Chicago and Golden State in 2000-2001) get the top two final draft positions in either order is 0.2182 $\left(\frac{120}{1000-250-200}\right)$. Note that the $\mathrm{X}$ in both Table 


\begin{tabular}{|c|c|c|c|}
\hline Team & $\begin{array}{c}\text { 2000-2001 Regular Season Record } \\
\text { (Games Won - Games Lost) }\end{array}$ & Chances & Probability \\
\hline Chicago & $15-67$ & 250 & 0.2500 \\
\hline Golden State & $17-65$ & 200 & 0.2000 \\
\hline Washington & $19-63$ & 157 & 0.1570 \\
\hline Vancouver & $23-59$ & 120 & 0.1200 \\
\hline Atlanta & $25-57$ & 89 & 0.0890 \\
\hline New Jersey & $36-56$ & 64 & 0.0640 \\
\hline Cleveland & $30-52$ & 44 & 0.0440 \\
\hline LA Clippers & $31-51$ & 29 & 0.0290 \\
\hline Detroit & $32-50$ & 18 & 0.0180 \\
\hline Boston & $36-46$ & 11 & 0.0110 \\
\hline Denver & $40-42$ & 7 & 0.0070 \\
\hline Seattle & $44-38$ & 6 & 0.0060 \\
\hline Houston & $45-37$ & 5 & 0.0050 \\
\hline Totals & & 1000 & 1.00 \\
\hline
\end{tabular}

Table 3. NBA Draft Lottery Probabilities - New System

\section{New System}

Pick Probability Calculation

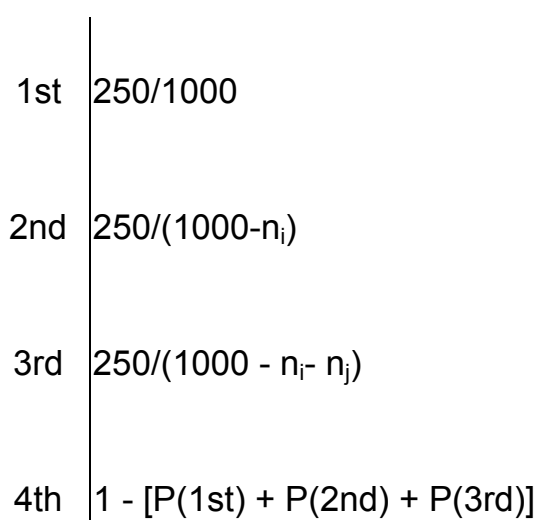

\section{Old System}

Pick Probability Calculation

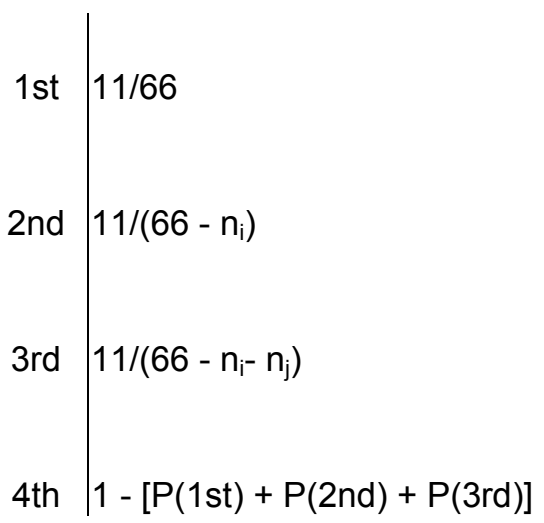

Table 4. Draft Lottery Probability Calculations for the Team with the Worst Record 
5 and Table 6 indicates the respective probability is zero (since we assume that the fourth worst team will receive the third pick and hence, cannot also receive either the first or second final draft positions). Table 6 shows how the Vancouver (fourth worst record in 2001) Grizzlies' chance of obtaining the third pick changes as we vary the teams that acquire the first and second picks in the 2000-2001 season under the new system. It is clear the Grizzlies' chance of obtaining the third pick increases when the worst teams receive the top two picks as opposed to when the best non-playoff teams receive them. Also, we will demonstrate how the new system favors Vancouver (compared to the old system) by comparing the probabilities of the two systems simultaneously.

Inspecting Tables 5 and 6 , the probability that the Grizzlies obtain the third pick given the first and second final draft positions go to the teams with the first and second initial draft position is 0.1778 under the old system and 0.2182 under the new system. Under both systems, the probability Vancouver acquires the third pick decreases as teams with fewer chances, i.e., better teams, receive the first and second picks. Under the old system, the difference between probabilities at the upper left corner and the lower right corner varies considerably less than those under the new system. That is, the difference in Vancouver being awarded the third pick with the first and second picks going to the twelfth and thirteenth worst ranked teams, as opposed to the first and second worst teams, is much larger under the new system.

\section{THE FOURTH WORST TEAM - UNCONDITIONAL PROBABILITY OF RECEIVING THE THIRD PICK}

Now that we have computed the conditional probabilities under both systems and compared the old and new systems, we shall find the unconditional probability of the fourth worst team moving up one draft position. We define the event $A$ as the fourth worst non-playoff team moving up in the draft to acquire the third overall selection, regardless of the teams that receive the first two picks. Then, $P(A)$ is found by calculating $\mathrm{P}\left(\mathrm{A} \cap \mathrm{B}_{\mathrm{i}, \mathrm{j}}\right)$ for all possible pairs of teams getting the first two picks, $B_{i, j}$. The collection of $B_{i, j}$ are a set of mutually exclusive and exhaustive events as seen in Figure 1. Then from the basic laws of probability [4],

$$
\begin{aligned}
\mathrm{P}(\mathrm{A}) & =\sum_{\mathrm{i}} \sum_{\mathrm{j}} \mathrm{P}\left(\mathrm{A} \cap \mathrm{B}_{\mathrm{i}, \mathrm{j}}\right)=\sum_{\mathrm{i}} \sum_{\mathrm{j}} \mathrm{P}\left(\mathrm{A} \mid \mathrm{B}_{\mathrm{i}, \mathrm{j}}\right) \cdot \mathrm{P}\left(\mathrm{B}_{\mathrm{i}, \mathrm{j}}\right) \text { where } \mathrm{i}<\mathrm{j} \\
& =\mathrm{P}\left(\mathrm{A} \mid \mathrm{B}_{1,2}\right) \cdot \mathrm{P}\left(\mathrm{B}_{1,2}\right)+\ldots+\mathrm{P}\left(\mathrm{A} \mid \mathrm{B}_{12,13}\right) \cdot \mathrm{P}\left(\mathrm{B}_{12,13}\right)
\end{aligned}
$$

where $A$ is the unconditional event that the team with the fourth worst record moves up in the draft to receive the third pick and $B_{i, j}$ is the event that teams with rank $i$ and rank $j$ receive the first two picks in either order. In other words, one can calculate the probability of event $A$ by summing up probabilities from the intersections formed by the mesh ( $B_{i, j}$ 's) forced upon $A$ as seen in Figure 1.

Let $n_{i}$ be the number of chances assigned to team with rank $\mathrm{i}$ from either Table 1 or Table 3 , respectively, and $n_{j}$ be the chances for team with rank $j$. For example, $\mathrm{n}_{4}$ is the number of chances assigned to the fourth worst team. Then
$P(A)$ is the unconditional probability that the team with the fourth worst record (Vancouver in 2001) receives the third overall pick in the draft regardless of who receives the first two picks. In general, the conditional probabilities in (1) can be calculated by

$$
\mathrm{P}\left(\mathrm{A} \mid \mathrm{B}_{\mathrm{i}, \mathrm{j}}\right)=\mathrm{n}_{4} /\left(1000-\mathrm{n}_{\mathrm{i}}-\mathrm{n}_{\mathrm{j}}\right)
$$

where each $P\left(A \mid B_{i j}\right)$ is given in Tables 5 and 6. To calculate $P\left(B_{i, j}\right)$, one must consider that order does not matter, i.e., team i could receive the first pick and team $\mathrm{j}$ could receive the second pick or vice versa. Mathematically, $P\left(B_{i, j}\right)=P($ team i gets the 


\begin{tabular}{|c|c|c|c|c|c|c|c|c|c|c|c|}
\hline \begin{tabular}{|c|} 
Team i \\
Team j
\end{tabular} & $\mathbf{1}$ & $\mathbf{2}$ & $\mathbf{3}$ & $\mathbf{4}$ & $\mathbf{5}$ & $\mathbf{6}$ & $\mathbf{7}$ & $\mathbf{8}$ & $\mathbf{9}$ & $\mathbf{1 0}$ & $\mathbf{1 1}$ \\
\hline $\mathbf{1}$ & & 0.1778 & 0.1739 & $\mathrm{X}$ & 0.1667 & 0.1633 & 0.1600 & 0.1569 & 0.1538 & 0.1509 & 0.1481 \\
\hline $\mathbf{2}$ & & & 0.1702 & $\mathrm{X}$ & 0.1633 & 0.1600 & 0.1569 & 0.1538 & 0.1509 & 0.1481 & 0.1455 \\
\hline $\mathbf{3}$ & & & & $\mathrm{X}$ & 0.1600 & 0.1569 & 0.1538 & 0.1509 & 0.1481 & 0.1455 & 0.1429 \\
\hline $\mathbf{4}$ & & & & & $\mathrm{X}$ & $\mathrm{X}$ & $\mathrm{X}$ & $\mathrm{X}$ & $\mathrm{X}$ & $\mathrm{X}$ & $\mathrm{X}$ \\
\hline $\mathbf{5}$ & & & & & & 0.1509 & 0.1481 & 0.1455 & 0.1429 & 0.1404 & 0.1379 \\
\hline $\mathbf{6}$ & & & & & & & 0.1455 & 0.1429 & 0.1404 & 0.1379 & 0.1356 \\
\hline $\mathbf{7}$ & & & & & & & & 0.1404 & 0.1379 & 0.1356 & 0.1333 \\
\hline $\mathbf{8}$ & & & & & & & & & 0.1356 & 0.1333 & 0.1311 \\
\hline $\mathbf{9}$ & & & & & & & & & & 0.1311 & 0.1290 \\
\hline $\mathbf{1 0}$ & & & & & & & & & & & 0.1270 \\
\hline $\mathbf{1 1}$ & & & & & & & & & & & \\
\hline
\end{tabular}

Table 5. Conditional Probability of the Fourth Worst Team Obtaining the Third Pick Under the Old System.

\begin{tabular}{|c|c|c|c|c|c|c|c|c|c|c|c|c|c|}
\hline \begin{tabular}{|c|} 
Team i \\
Team j
\end{tabular} & $\mathbf{1}$ & $\mathbf{2}$ & $\mathbf{3}$ & $\mathbf{4}$ & $\mathbf{5}$ & $\mathbf{6}$ & $\mathbf{7}$ & $\mathbf{8}$ & $\mathbf{9}$ & $\mathbf{1 0}$ & $\mathbf{1 1}$ & $\mathbf{1 2}$ & $\mathbf{1 3}$ \\
\hline $\mathbf{1}$ & & 0.2182 & 0.2034 & $\mathrm{X}$ & 0.1815 & 0.1749 & 0.1683 & 0.1681 & 0.1639 & 0.1624 & 0.1615 & 0.1613 & 0.1611 \\
\hline $\mathbf{2}$ & & & 0.1866 & $\mathrm{X}$ & 0.1688 & 0.1630 & 0.1573 & 0.1571 & 0.1535 & 0.1521 & 0.1513 & 0.1511 & 0.1509 \\
\hline $\mathbf{3}$ & & & & $\mathrm{X}$ & 0.1592 & 0.1540 & 0.1489 & 0.1487 & 0.1455 & 0.1442 & 0.1435 & 0.1434 & 0.1432 \\
\hline $\mathbf{4}$ & & & & & $\mathrm{X}$ & $\mathrm{X}$ & $\mathrm{X}$ & $\mathrm{X}$ & $\mathrm{X}$ & $\mathrm{X}$ & $\mathrm{X}$ & $\mathrm{X}$ & $\mathrm{X}$ \\
\hline $\mathbf{5}$ & & & & & & 0.1417 & 0.1373 & 0.1371 & 0.1344 & 0.1333 & 0.1327 & 0.1326 & 0.1325 \\
\hline $\mathbf{6}$ & & & & & & & 0.1335 & 0.1333 & 0.1307 & 0.1297 & 0.1292 & 0.1290 & 0.1289 \\
\hline $\mathbf{7}$ & & & & & & & & 0.1294 & 0.1270 & 0.1261 & 0.1255 & 0.1254 & 0.1253 \\
\hline $\mathbf{8}$ & & & & & & & & & 0.1268 & 0.1259 & 0.1254 & 0.1253 & 0.1251 \\
\hline $\mathbf{9}$ & & & & & & & & & & 0.1236 & 0.1231 & 0.1230 & 0.1228 \\
\hline $\mathbf{1 0}$ & & & & & & & & & & & 0.1222 & 0.1221 & 0.1220 \\
\hline $\mathbf{1 1}$ & & & & & & & & & & & & 0.1216 & 0.1215 \\
\hline $\mathbf{1 2}$ & & & & & & & & & & & & & 0.1213 \\
\hline $\mathbf{1 3}$ & & & & & & & & & & & & & \\
\hline
\end{tabular}

Table 6. Conditional Probability Calculation for the Fourth Worst Team Obtaining the Third Pick Under the New System.

first pick) $P($ team $j$ gets the second pick given team $i$ gets the first pick) $+P$ (team $j$ gets the first pick) $P($ team i gets the second pick given team $\mathrm{j}$ gets the first pick). In general,

$$
P\left(B_{i, j}\right)=\left(n_{i} / 1000\right) \cdot\left(n_{j} /\left(1000-n_{i}\right)\right)+\left(n_{j} / 1000\right) \cdot\left(n_{i} /\left(1000-n_{j}\right)\right)
$$




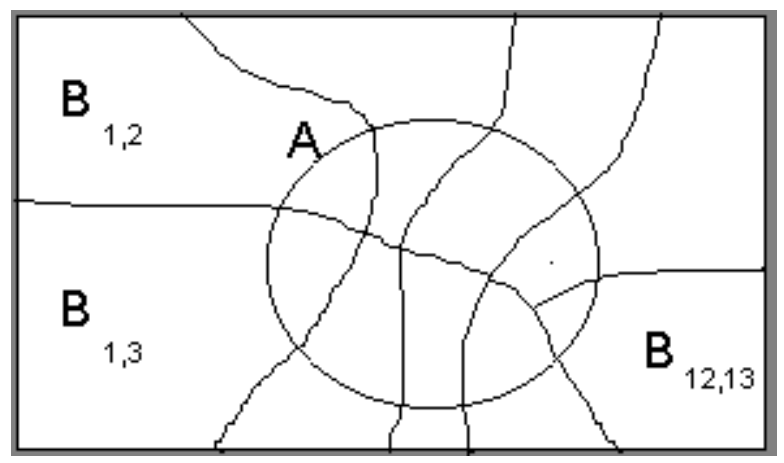

Figure 1. Event A together with the Partition of the Sample Space into Exhaustive and Mutually Exclusive sets, $B_{i, j}$

Using (1), (2) and (3), $A \cap B_{i, j}$ probabilities are given, under the new system, in Table 7 for all ${ }_{12} \mathrm{C}_{2}=66$ possible pairs of teams receiving the top two picks. Now, $P(A)$ under the new system is calculated by summing all values in Table 7 . The unconditional chance that Vancouver in 2001 receives the third pick is 0.1341 . Similar calculations are performed under the old system (although not presented in a table analogous to Table 7) for all ${ }_{10} \mathrm{C}_{2}=45$ pairs.

\section{FOURTH WORST TEAM - UNCONDITIONAL PROBABILITY OF RECEIVING THE SECOND PICK}

We next compute the unconditional probability that the team with the fourth worst record moves up to the second position. This will require us to compute the probability of $C$ where $C$ is the event that the team with the fourth worst record moves up in the draft to receive the second pick (second final draft position). Let $\mathrm{B}_{\mathrm{i}}$ be the event that a team with rank $\mathrm{i}$ receives the first pick and $\mathrm{n}_{\mathrm{i}}$ be the respective number of chances assigned to team with rank $\mathrm{i}$ (from Table 1 or Table 3 , respectively). Then, analogous to $P(A)$ in (1),

$$
\begin{aligned}
& P(C)= \\
& \quad \sum_{i} P\left(C \cap B_{i}\right)=\sum_{i} P\left(C \mid B_{i}\right) \cdot P\left(B_{i}\right)
\end{aligned}
$$

where $P\left(C \mid B_{i}\right)$ is the conditional probability that the team with the fourth worst record receives the second overall pick given a team with rank $\mathrm{i}$ receives the first pick and $P\left(B_{i}\right)$ is the probability that team $i$ receives the first pick. In particular, each $P\left(C \mid B_{i}\right)$ is obtained using

and

$$
\mathrm{P}\left(\mathrm{C} \mid \mathrm{B}_{\mathrm{i}}\right)=\left(\mathrm{n}_{4} /\left(1000-\mathrm{n}_{\mathrm{i}}\right)\right)
$$

$$
\mathrm{P}\left(\mathrm{B}_{\mathrm{i}}\right)=\left(\mathrm{n}_{\mathrm{i}} / 1000\right) .
$$

Using (4), (5) and (6), the chance that the fourth worst team receives the second pick can be calculated by summing the ${ }_{12} \mathrm{C}_{1}=12$ individual probabilities in the last column of Table 8. Under the new system, the chance of the fourth worst team receiving the second pick, after summing the last column in Table 8, is 0.1270 .

\section{THE FOURTH WORST TEAM- REMAINING PROBABILITIES}

We next discuss how to calculate the probability that the team with the fourth worst record receives the fourth draft position or drops to either the fifth, sixth or seventh position. Recall that only the top three final draft positions are determined by the draft lottery, i.e., once the first three are drawn, the remaining positions are automatically determined by inverse order of wins. Thus, staying in the fourth position requires that the top three final draft positions be filled by the worst three teams 


\begin{tabular}{|c|c|c|c|c|c|c|c|c|c|c|c|c|c|}
\hline \begin{tabular}{|c|c|c|c|c|c|c|c|c|c|}
\hline Team i \\
Team j
\end{tabular} & $\mathbf{1}$ & $\mathbf{2}$ & $\mathbf{3}$ & $\mathbf{4}$ & $\mathbf{5}$ & $\mathbf{6}$ & $\mathbf{7}$ & $\mathbf{8}$ & $\mathbf{9}$ & $\mathbf{1 0}$ & $\mathbf{1 1}$ & $\mathbf{1 2}$ & $\mathbf{1 3}$ \\
\hline $\mathbf{1}$ & & 0.0282 & 0.0201 & $\mathrm{X}$ & 0.0084 & 0.0080 & 0.0044 & 0.0029 & 0.0017 & 0.0010 & 0.0007 & 0.0006 & 0.0005 \\
\hline $\mathbf{2}$ & & & 0.0143 & $\mathrm{X}$ & 0.0061 & 0.0058 & 0.0032 & 0.0021 & 0.0013 & 0.0008 & 0.0005 & 0.0004 & 0.0003 \\
\hline $\mathbf{3}$ & & & & $\mathrm{X}$ & 0.0044 & 0.0042 & 0.0023 & 0.0015 & 0.0009 & 0.0005 & 0.0003 & 0.0003 & 0.0002 \\
\hline $\mathbf{4}$ & & & & & $\mathrm{X}$ & $\mathrm{X}$ & $\mathrm{X}$ & $\mathrm{X}$ & $\mathrm{X}$ & $\mathrm{X}$ & $\mathrm{X}$ & $\mathrm{X}$ & $\mathrm{X}$ \\
\hline $\mathbf{5}$ & & & & & & 0.0018 & 0.0010 & 0.0006 & 0.0004 & 0.0001 & 0.0001 & 0.0001 & 0.0001 \\
\hline $\mathbf{6}$ & & & & & & & 0.0010 & 0.0006 & 0.0004 & 0.0002 & 0.0001 & 0.0001 & 0.0001 \\
\hline $\mathbf{7}$ & & & & & & & & 0.0003 & 0.0002 & 0.0001 & 0.0001 & 0.0001 & 0.0001 \\
\hline $\mathbf{8}$ & & & & & & & & & 0.0001 & 0.0001 & 0.0001 & 0.0000 & 0.0000 \\
\hline $\mathbf{9}$ & & & & & & & & & & 0.0000 & 0.0000 & 0.0000 & 0.0000 \\
\hline $\mathbf{1 0}$ & & & & & & & & & & & 0.0000 & 0.0000 & 0.0000 \\
\hline $\mathbf{1 1}$ & & & & & & & & & & & & 0.0000 & 0.0000 \\
\hline $\mathbf{1 2}$ & & & & & & & & & & & & & 0.0000 \\
\hline $\mathbf{1 3}$ & & & & & & & & & & & & & \\
\hline
\end{tabular}

Table 7. $\mathrm{P}\left(\mathrm{A} \cap \mathrm{B}_{\mathrm{i}, \mathrm{j}}\right)$ under the New System.

in any order. Hence, of the $1320(12 \cdot 11 \cdot 10)$ possible arrangements of twelve teams that could receive the first three picks (we exclude the fourth worst team) in any order under the new system (or 720 possible arrangements under the old), only six $\left.\left(3 ! \cdot{ }_{3} \mathrm{C}_{3} \cdot{ }_{9} \mathrm{C}_{0}\right)\right)$ result in the three worst teams receiving the top three picks. Under the new system, the fourth worst team has a 0.1000 probability $(0.0350$ under the old system) of receiving the fourth final draft position.

To calculate the probability of the fourth team receiving the fifth pick under the new system, we need to look at $3 ! \cdot\left({ }_{3} \mathrm{C}_{2} \cdot{ }_{9} \mathrm{C}_{1}\right)=162$ combinations of 1320 of the remaining nine receive the top three picks in any order $\left(3 ! \cdot\left({ }_{3} \mathrm{C}_{2} \cdot{ }_{7} \mathrm{C}_{1}\right)=126\right.$ under the old system). To find the probability of the sixth pick under the new system, $3 ! \cdot\left({ }_{3} \mathrm{C}_{1} \cdot{ }_{9} \mathrm{C}_{2}\right)=648$ combinations of 1320 where one of the worst three teams and two of the remaining nine receive the top three picks $\left(3 ! \cdot\left({ }_{3} \mathrm{C}_{1} \cdot{ }_{7} \mathrm{C}_{2}\right)=378\right.$ under the old system). Lastly, to find the probability of the fourth worst team receiving the seventh pick (without simply using the complementary rule from all previous where two of the worst three teams and one probabilities) under the new system, we examine $3 ! \cdot\left({ }_{3} \mathrm{C}_{0} \cdot{ }_{9} \mathrm{C}_{3}\right)=504$ combinations

\begin{tabular}{|c|c|c|c|}
\hline Team i & $\mathrm{P}\left(\mathrm{C} \mid \mathrm{B}_{\mathrm{i}}\right)$ & $\mathrm{P}\left(\mathrm{B}_{\mathrm{i}}\right)$ & $\mathrm{P}\left(\mathrm{C} \cap \mathrm{B}_{\mathrm{i}}\right)$ \\
\hline 1 & 0.1600 & 0.2500 & 0.0400 \\
\hline 2 & 0.1500 & 0.2000 & 0.0300 \\
\hline 3 & 0.1423 & 0.1570 & 0.0223 \\
\hline 5 & 0.1300 & 0.0770 & 0.0100 \\
\hline 6 & 0.1299 & 0.0760 & 0.0099 \\
\hline 7 & 0.1255 & 0.0440 & 0.0055 \\
\hline 8 & 0.1236 & 0.0290 & 0.0036 \\
\hline 9 & 0.1222 & 0.0180 & 0.0022 \\
\hline 10 & 0.1213 & 0.0110 & 0.0013 \\
\hline 11 & 0.1208 & 0.0070 & 0.0008 \\
\hline 12 & 0.1207 & 0.0060 & 0.0007 \\
\hline 13 & 0.1206 & 0.0050 & 0.0006 \\
\hline
\end{tabular}

Table 8. $\mathrm{P}\left(\mathrm{C} \cap \mathrm{B}_{\mathrm{i}}\right)$ under the New System. 


\begin{tabular}{|c|c|c|c|c|}
\hline & 1st Pick & 2nd Pick & $3^{\text {rd }}$ Pick & Overall \\
\hline Old System & 0.1212 & 0.1207 & 0.1197 & $\mathbf{0 . 3 6 1 6}$ \\
\hline New System & 0.1200 & 0.1270 & 0.1341 & $\mathbf{0 . 3 8 1 1}$ \\
\hline
\end{tabular}

Table 9. Probability that the Fourth Worst Team moves up in the Draft.

\begin{tabular}{|c|c|c|c|}
\hline & Moves Up & Stays Same & Drops \\
\hline Old System & 0.3616 & 0.0350 & 0.6034 \\
\hline New System & 0.3811 & 0.1000 & 0.5189 \\
\hline
\end{tabular}

Table 10. Probabilities for the fourth worst team to increase, stay the same or decrease its initial draft position (to its final draft position).

\begin{tabular}{|c|c|c|c|}
\hline Year & $\begin{array}{c}\text { NBA Team } \\
\text { (With Record) }\end{array}$ & $\begin{array}{c}\text { Final } \\
\text { Draft } \\
\text { Position } \\
\end{array}$ & $\begin{array}{l}\text { Player } \\
\text { Drafted }\end{array}$ \\
\hline $2002-2003$ & Miami (25-57) & 5 th & Dwyane Wade \\
\hline 2001-2002 & Denver (27-55) & 5 th & Nikoloz Tskitishvili \\
\hline $2000-2001$ & Vancouver (23-59) & 6 th & Shane Battier \\
\hline $1999-2000$ & Vancouver (22-60) & 2nd & Stromile Swift \\
\hline 1998-1999 & $\begin{array}{c}\text { Denver (14-36) } \\
\text { Traded pick to Toronto }\end{array}$ & 5th & Jonathon Bender \\
\hline 1997-1998 & Golden State (19-63) & 5 th & Vince Carter \\
\hline 1996-1997 & Denver (21-61) & 5 th & Tony Battie \\
\hline 1995-1996 & Milwaukee (25-57) & 4th & Stephon Marbury \\
\hline
\end{tabular}

Table 11. Actual NBA Draft results for the team with the fourth worst record from 1996 to present (Pro Basketball, 2003).

teams and three of the remaining nine receive the top three picks $\left(3 ! \cdot\left({ }_{3} \mathrm{C}_{0}{ }_{7} \mathrm{C}_{3}\right)=\right.$ 210 under the old system).

\section{DISCUSSION}

Table 9 provides a summary of the calculations for the chances of the team with the fourth worst record moving up in the draft to one of the first three positions under both the new and old systems. It is interesting that although the team with the fourth worst record's probability of obtaining the first overall selection slightly decreased with the implementation of the new system, their probability of moving up to any one of the first three positions increased.

Table 10 illustrates the probability that the team with the fourth worst record moves up to any of the top three picks, stays the same or drops to the fifth, sixth or seventh picks under both systems. It is 
noteworthy that the fourth worst team is more likely to drop rather than stay the same or increase its final draft position under either system.

Lastly, we look at the actual teams with the fourth worst record under the new system since 1996 (with the fourth initial draft position) and observe their final draft position. In Table 11, we see the fourth worst team increased its draft position only once (Vancouver in 2000), stayed the same only once (Milwaukee in 1996) and decreased its position six times! In particular, five of the eight times the fourth worst team drafted in the fifth position.

\section{CONCLUSIONS}

Our investigation into the probability theory behind the NBA Draft Lottery has been a very interesting experience. It is unfortunate that the NBA had to go to great lengths to implement these systems into their drafting process because of the potential for teams to deliberately lose games. This behavior greatly compromises the integrity of the sport and causes the quality of play at the end of the season to diminish. These NBA draft lottery systems have become more advantageous to the teams with the worst records while maintaining enough randomness to thwart other teams from throwing games.
With regard to the fourth worst team, we have demonstrated the differences between two methodologies for conducting the draft. It is clear the probability of the fourth worst non-playoff team moving up in the draft to the third selection regardless of the teams receiving the first two picks increased with the implementation of the new system. It was also shown that with the implementation of the new system, the probability for the team with the fourth worst record to obtain the first overall selection decreased while the probability of moving up in the draft to either the second or third position increased. It is also more likely that the team with the fourth worst record will drop in the draft lottery under either system, compared to staying in the same position or moving up.

\section{REFERENCES}

1. NBA. (2003). Evolution of the Draft Lottery. See http://www.nba.com/ history/draft_evolution.html.

2. NBA. (2003). Year-by-Year Lottery Picks. See http://www.nba.com/ history/ lottery_picks.html.

3. NBA. (2003). Year-by-Year Lottery Probabilities. See http://www.nba.com/ history/lottery_probabilities.html.

4. Ross, S. A First Course in Probability Sixth Edition. (Prentice Hall, New Jersey, 2002).

5. Pro Basketball. (2003). Final NBA Standings. http://www.infoplease.com/ ipsa/A0003691.html. 


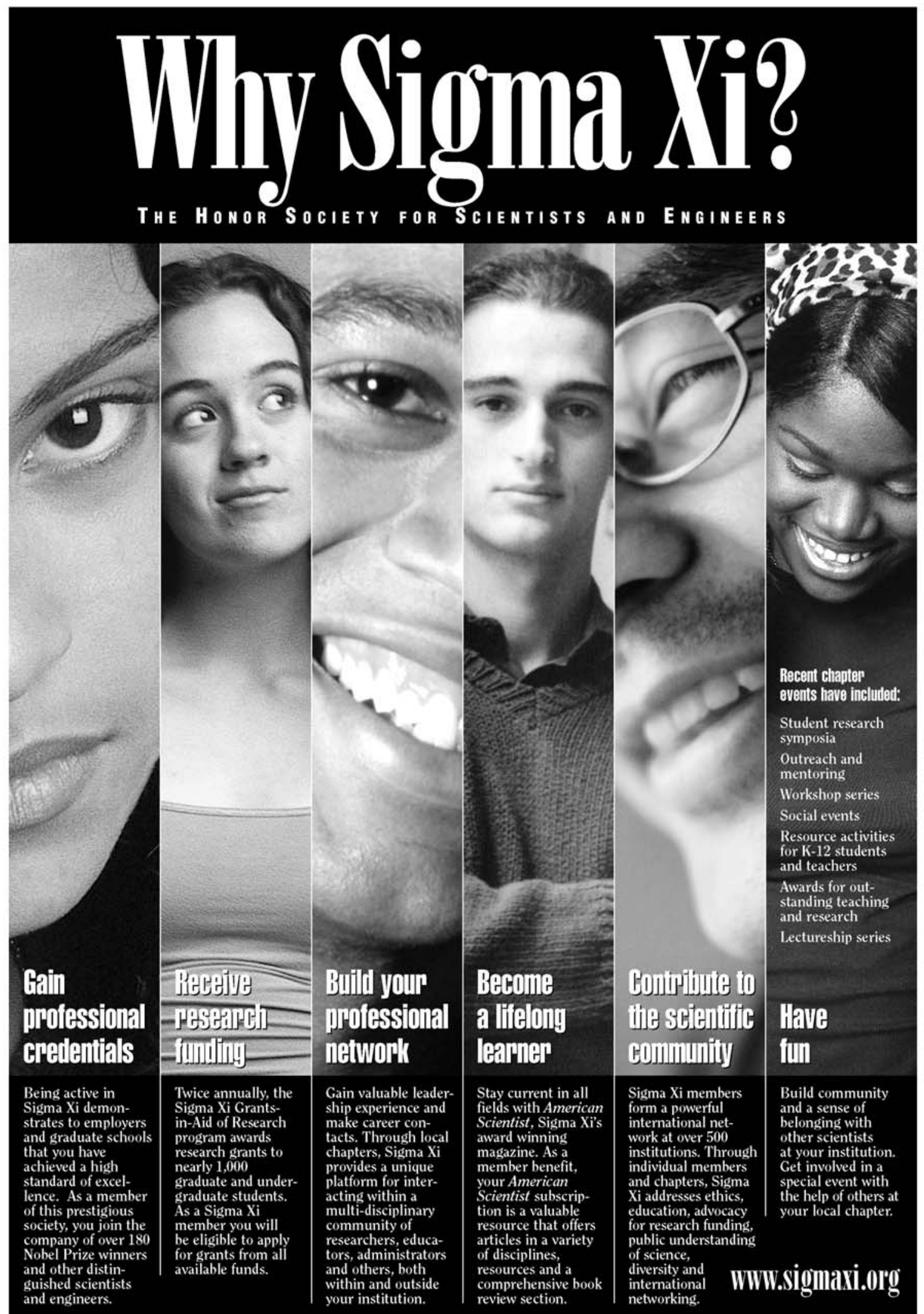

Sigma Xi, The Seientific Research Society • 98 Alexander Drive • P.O. Box 13975 • Research Triangle Park, NC 27708 • 818-549-4691 • 800-243-6534 